\title{
DETERMINATION OF DISSOLVED CONCENTRATIONS OF POLYCYCLIC AROMATIC HYDROCARBONS IN RIVER
}

\author{
MUHAMMAD NURADDEEN BUI \\ DEPARTMENT OF CHEMISTRY, COLLEGE OF EDUCATION, ARGUNGU, KEBBI \\ STATE,NIGERIA \\ Corresponding Email: jaopara@yahoo.com
}

Keywords: SR-PS, GC-MS, PAH, PRC and Sampling rate.

\begin{abstract}
This study shows the sensitivity of using silicone rubber passive sample R-PS) an gas chromatography with mass spectrometer (GC-MS) detection for monitorin s and ia ficati n of polycyclic aromatic hydrocarbons in surface water systems. The an ysis is per aed for eighteen PAHs compounds after pre-concentration using Soxhee troction pethod. By comparison, a total of 13 PAHs were detected in the spot wate sampl of wh ch none was quantifiable. The freely dissolved PAH concentrations were four range fro $0 / 7 \mathrm{ng} / \mathrm{L}$ to 0.76 $\mathrm{ng} / \mathrm{L}$ at Ugieriver. The use of fluorine $\mathrm{d}_{10}$ as Performance efer compound(PRC) gives a sampling rates of 8.14 (L/day) for silicone rubber san andysis of PAHs concentrations suggest the contaminants are mainly $f$ om pyrolytic so rces. Overall it can be concluded that SR-PS are viable alternatives in the env nmental monitoring of PAHs.
\end{abstract}

\section{INTRODUCTION}

The hydrosphere environment can be si jo to the input of dissolved organic and inorganic hazardous substances from a variety of 0 ices, ach as through atmospheric deposition, industrial and agricultural processes rage or ndustrial wastewater discharges, riverine inputs and poor environmental manager nt (b elogu e 12013b). A great number of these pollutants tend to be persistent in the enyiro ent a often highly toxic to aquatic organisms and may ultimately be of conce 10 tho nsumer of these aquatic organisms (Emelogu et al 2012; Emelogu et al 2013a).

Sampling and ar lysis surface waters for a broad range of environmentally relevant persistent pollutants polycyo aromatic hydrocarbons present significant analytical challenges, primarily as a res at of w concen ations and incomplete phase separation between particle-bound and dissolved tes onec ss and Booij 2012). Until recently regulatory monitoring of water has generally relied o. e colle con and analysis of "spot" samples for total or dissolved pollutant concentro such are sampling approaches can often provide an unrepresentative picture of tempo (e.s seasona variation) and spatial charges (point source discharges).Additionally environ rong requires sensitive analytical methodologies that allow for detection of persistent utants in water biota and the water column itself.

Passive Mpling (PS) is now internationally recognised as a promising technique in the area of contaminarts analysis, where careful selection and deployment of appropriate passive sampling devices followed by targeted analysis can allow for the calculation of dissolved phase, time weighted, trace level water concentrations of a range of environmentally relevant pollutants (Vrana et al 2005; Kot-wasik et al 2005). Interest in passive sampling techniques for surface water monitoring to support legislative requirements, to track pollutant fate and to aid in toxicological/bioaccumulation studies continues to grow (Kot, Zabiegadla and Namiesnik 2000).

Water sampling for contaminant analysis can be completed by either direct or indirect means (with biomonitor/bioindicator organisms e.g. mussels). Currently, the most commonly used method for measuring levels of chemical pollutants in water is via the collection of discrete spot/grab/bottle samples, followed by extraction and instrumental analysis (Booij et al 2000). However the ongoing 
development of techniques such as passive sampling can provide a number of advantages over conventional techniques. According to Madrid and Zayas (2007), spot sampling can be carried out using three different options. Direct filling of sample bottle is applied to surface waters, dedicated water samplers are used for deep waters and use of peristaltic pumps for larger volume of water. Conventional sampling approaches often suffer from several limitations and are not appropriate for long-term monitoring of the presence of organic contaminants in water. This is because sample taken by snapshot may fail to identify temporal changes in contaminant and chemically liable volatile compounds can be altered during transport and storage of samples.

Passive sampling (PS) involves the measurement of analyte concentration as a weighted function of the time of sampling(the concentration of the analyte is integrated over the sampling period), as opposed to active sampling which involves the collection of samples at diffmant time intervals using an external energy source (Kot, Zabiegba and Namiesnik 2000). Vr wa et a. 005) defined PS in its broadest sense as any sampling technique based on free flow of 9lyte molo les from the sampled medium to a receiving phase in a sampling device. The $\mathrm{m}$ in $\mathrm{d}$, $\mathrm{g}$ forc and separation mechanism are based on the differences in analyte concentration oetween th vodia. The net flow of analyte molecules from one medium to the other cor ques $y$ il equ orium is established in the system, or until the sampling period is completed ( $C$ rec Nam nik 2002).

In PS analytes are absorbed or adsorbed in/on a suitable me um with he posive sampler, known as a reference or receiving phase. This can be a soly $\mathrm{ch}$ hemical is ont or a porous adsorbent. The reference/receiving phase is then exposed the pr phase to "sample" the dissolved contaminants (Vrana et al. 2005). PS devices arto subseq. derive dissolved phase contaminant concentration in rmation or "extacts" may be of use in biomarker exposure experiments.

Several passive sampling devices used for monitoring nge of s bstances have been developed. According to Smith and Booij (2012) water amplers houring hydrophobic pollutants are characterized into macro and micro ones. An micro samplers are solid-phase micro extractionextraction (SPME) and membrane en los a live coating (MESCO). Macro passive samplers are made from single organic mlymer, 1 example; strips sampler made from low-density polyethylene (LDPE), polydimethy silox e (PDM yor polyoxymethylene (POM). For monitoring of hydrophobic organic pollut in sater en ronment semi-permeable membrane devices (SPMDs), MESCO, Chemca r, r, Animeters and Polar Organic Chemical Integrative Sampler (POCIS) are all do mented (cins et al, 1993; Kingston et al, 2000; Vrana, Paschke and Popp, 2006).

Smedes (2007), sugg to d that material with a non-polar structure can essentially function as a passive sampler $/ \mathrm{S}$ ). Rusina et (2007) also proposed that silicone rubbers can be used as reference phase "or PS cause of their high partition co-efficients and low transport resistances. Silicone rubber $p_{a}$ e samp s consist of PDMS sheets, secured to a stainless steel frame. Figure 1 below st the ch ical structure of PDMS.

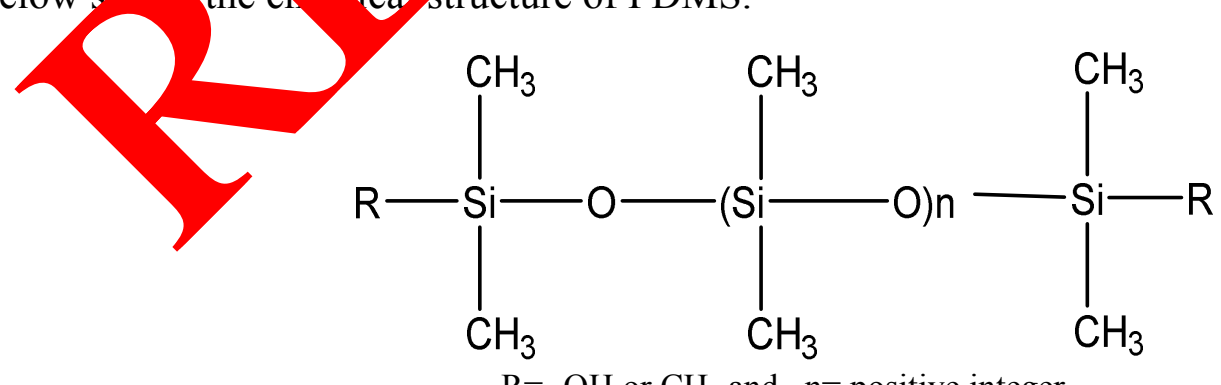

$\mathrm{R}=-\mathrm{OH}$ or $\mathrm{CH}_{3}$ and $\mathrm{n}=$ positive integer

Figure 1: Chemical structure of the Polydimethylsiloxane (PDMS) polymer.

Yates et al (2007) measured the silicone rubber-water partition co-efficients $\left(\mathrm{K}_{\mathrm{sw}}\right)$ of a series of hydrophobic organic compounds (PCBs and PAHs), with octanol-water partition co-efficient (expressed as $\log \mathrm{K}_{\mathrm{ow}}$ ) values for the compounds studied ranging from 3.3 to 8.2 This confirmed that partitioning into the silicone rubber is strongly determined by compound hydrophobicity. This 
in turn suggests that $\log \mathrm{K}_{\mathrm{ow}}$ is a good predictor of $\log \mathrm{K}_{\mathrm{sw}}$ and that absorption is the main mechanism for accumulation of analytes into the silicone rubber polymer.

The application of silicone rubber passive samplers for monitoring hydrophobic contaminants has been gaining importance in recent years. Freely dissolved concentration in environmental medium and sampling rates of added performance reference compounds (PRCs) can be determined using the sampler water partion co-efficient and concentration in the silicone rubber reference phase that equilibrates with the surrounding medium (Yates et al 2007; Meyer et al 2003; Huckins and Booij 2006).

\section{MATERIALS AND METHODS}

\subsection{Materials}

$\mathrm{AlteSil}^{\mathrm{TM}}$ silicone rubber sheet manufactured from translucent, food grade silico e rubber $0 \mathrm{x}$ $600 \mathrm{~mm}, 0.5 \mathrm{~mm}$ thick) obtained from Altec products, Ltd, Cornwall, UK. The a vtical-re ent grade dichloromethane, methanol, ethyl acetate, acetone, Sodium sulpha silica (all rom Fischer scientific Ltd UK), iso-hexane (Rathburn chemicals Ltd, Scotl nd, U, wero cmicals used as solvents. A $200 \mathrm{gmL}^{-1}$ mixed PAH standard solution contan 16 PAH compounds (naphthalene, acenaphthylene, acenaphthene, fluorene, phenanth 110 , an cene, Muoranthene, pyrene, benzo[a]anthracene, chrysene, benzo[b]fluor ene, o $k]$ fluoranthene, benzo $[a]$ pyrene, indeno $[1,2,3-c, d]$ pyrene, benzo $[g, h, i]$ peryler ano ibenzo $[a, i]$ anthracene) was purchased from sigma Aldrich, UK. PAH-Mix 31 containi trve (5) teratedinternal standards (acenaphthene- $\mathrm{d}_{10}$, phenanthrene- $\mathrm{d}_{10}$, naphthalene- $\mathrm{D}_{8}$ orysene- $\mathrm{d}_{12}$ and crylene $\mathrm{d}_{12}$ ) as well as Fluorene- $\mathrm{d}_{10}$ (usedas performance reference compound during the spiking process) were obtained from QMX Laboratories, Essex, UK. A Gerhardt Sox rm $^{\circledR}$ syster and Soxhlet ${ }^{\circledR}$ apparatus were used for the pre-extraction and deployed silicone strip tractio respectively whilst a Genevac evaporation unit was used for reducing the volu of solvents.

\subsection{Methods}

\subsection{1}

Preparation of Silic one

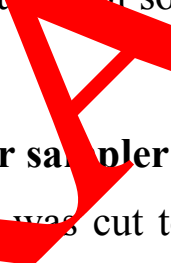

The silicone rubber sheet $(0.5 \mathrm{nh}$ icl made for mounting piece of neo to rim using a paper puncher. The prepared sheets were preextracted (Soxhlet extrac, with et, etate using Gerhardt Soxtherm ${ }^{\circledR}$ system in order to remove any residues li olig ars, addituves from silicone rubber production process or siloxanes which can be co-ex anted with Jyte and consequently interfere with the GC analysis either by coating the injercion $\hat{b}$ ort or the iner or even the column leading to poor chromatographic separation.

$150 \mathrm{~mL}$ cetate th a ti-bumping granules in Gerhardt Soxhlet tubes was used to extract five (5) stri s of s cone ru er sheets for four (4) hours. After cooling, the Silicone rubber strips were put in a ide remains or byl acetate making it ready for spiking.

\subsubsection{Spiking of Silicone Rubber Sheets}

The extracted silicone rubber strips were loaded with performance reference compounds (PRCs) according to the spiking method describes by Smedes and Booij et al (2012) and Yates et al (2007). Fluorene- $\mathrm{d}_{10}$ and PCB mix90 were used as PRCs, although the PCB mix 90 was not analysed in this analysis due to time constraints. Consequently only fluorine- $\mathrm{d}_{10}$ will be taken as the PRC.

Briefly, $150 \mathrm{~mL}$ methanol was measured into a rinsed wide open mouth glass jar, and $1 \mathrm{~mL}$ of flourene- $\mathrm{d}_{10}$ and PCB mix90 solution was added to the jar. Twenty seven (27) silicone rubber strips were added, the jar sealed and covered in foil to reduce PAH exposure to light, and placed on a shaker for two hours. After which, $37.5 \mathrm{~mL}$ water was added to obtain $80 \%$ methanol solution. The 
strips were shaken for a further four hours and then $112.5 \mathrm{~mL}$ of water was added to obtain a $50 \%$ methanol solution. The strips were then shaken for twenty four hours before being transferred to a jar without any solution ready for site deployment.

\subsubsection{Extraction of PAHs in Silicone Rubber Sampler}

The samplers were extracted following the procedure obtained from Booijet al 2012 and Yates et al 2013. Briefly the silicone rubber samplers were extracted using a soxhlet apparatus with $150 \mathrm{~mL}$ solvent of methanol in $500 \mathrm{~mL}$ round bottomed flasks; anti-bumping granules and $100 \mu \mathrm{L}$ of deuterated PAHs-Mix 31 (100 ppm internal standard) were added to each flask. Both field and procedural blank silicone rubber strips were placed in separate Soxhlets column using long tweezers and the extraction process was allowed to proceed for six hours. The round botton were rinsed twice with iso-hexane to ensure all the extract was transferred. $\mathrm{Th}$ extract yere subsequently stored in the fridge. The silicone rubber sheets were removed $m$ extracto and weighed after cooling.

\subsubsection{Extraction of PAHs in Water spot sample}

1 Litre of the sample collected from each site were measured ar a nans a d to separating funnel and then $50 \mathrm{~mL}$ and $100 \mu \mathrm{L}$ of dichloromethane (DCN nd $100 \mathrm{p}_{\mathrm{N}}$ iternal standard (deuterated PAHs) were added respectively and mixed. The ixtu vas alloy ed to settle on the stand for a while until two distinct layers were formed, a tre bott DCM layer collected. A further $50 \mathrm{~mL}$ of DCM was added to the water sample extracted as befy and the DCM fraction combined with the previous extract and stored at $4^{0} \mathrm{C}$.

\subsubsection{Clean-up procedure for extract}

The stored extracts obtained from spot water s and silicone rubber samplers were removed from the fridge and allowed to warm to room te pere being reduced to approximately 2 $\mathrm{mL}$ using the Genevac ${ }^{\circledR}$ evaporator. $10 \mathrm{~mL}$ of $i s$ nexane was subsequently added to the extracts obtained from silicone rubber strip ana duced $\mathrm{t}$ about $2 \mathrm{~mL}$ by heating in water bath (repeated until no distinct layers), to eva te 9 replace methanol. Approximately $2 \mathrm{~mL}$ of iso-hexane extract was obtained.

Both the water and silicor rubber sa ler extracts were cleaned up by passing through a glass column containing silic ge ing 1:3 v, DCM :iso-hexane as elution solvent. $50 \mathrm{~mL}$ of eluent were collected and $r$ u ed to vroximately $2 \mathrm{~mL}$ using the Genevac ${ }^{\circledR}$ evaporator syatem. The extract was transf red to a labely $\mathrm{GC}$ vial and reduced to about $1 \mathrm{~mL}$ using the nitrogen blowdown apparatus ady fo GCMS analysis.

\subsection{Methor}

\subsection{1 -MS nstrume, ation}

The gas on coupled with mass spectrometer (Shimadzu model GCMSQP2010) was used to ca out the PAHs analysis of the samples. The data obtained were acquired with instrument of ring in selected ion monitoring (SIM) mode which allows quick identification and quantification of the selected ions.

The GC used was equipped with a non-polar fused silica capillary column SLV - 5 MS (30m x 0.25 id x $0.25 \mu \mathrm{m}$ ) from Supelco (Milano, Italy). Ultra-pure $(99.999 \%)$ helium is used as a carrier gas with column flow rate of $1.00 \mathrm{~mL} / \mathrm{min}$. The samples extracts are injected using the splitless mode. The injector and oven temperatures were maintained at $280{ }^{0} \mathrm{C}$ and $40{ }^{0} \mathrm{C}$ respectively. The GC oven temperature program was: $40^{0} \mathrm{C}$ (held for $12 \mathrm{~min}$ ), ramped to $100^{\circ} \mathrm{C}$ at $35^{0} \mathrm{Cmin}^{-1}$, followed by a ramp at $15^{\circ} \mathrm{Cmin}^{-1}$ to $200^{\circ} \mathrm{C}$ (held for $3 \mathrm{~min}$ ), and finally ramped at $10^{0} \mathrm{Cmin}^{-1}$ to $300^{0} \mathrm{C}$ (held for $12 \mathrm{~min}$ ). The coupled mass spectrometer (quadrupole detector) operates with interface and ion source temperatures of $250^{\circ} \mathrm{C}$ and $200^{\circ} \mathrm{C}$ respectively. Apart from internal standards used the ions that will be monitored in this study were as follows: 


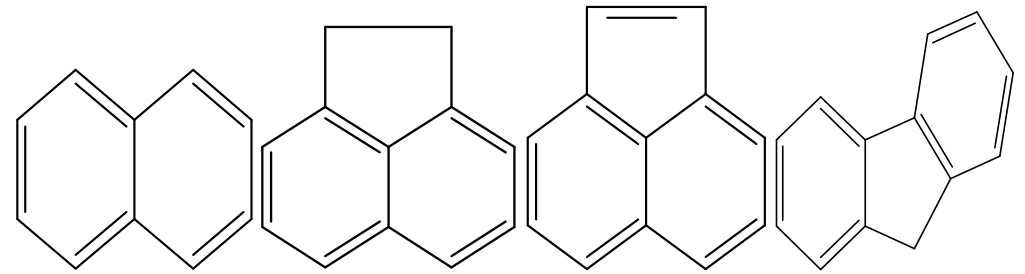

Naphthalene $\left(\mathrm{M}_{\mathrm{w}}=128\right)$ acenaphthene $\left(\mathrm{M}_{\mathrm{w}}=152\right)$ acenaphthylene $\left(\mathrm{M}_{\mathrm{w}}=153\right)$ Fluorine $\left(\mathrm{M}_{\mathrm{w}}=166\right)$

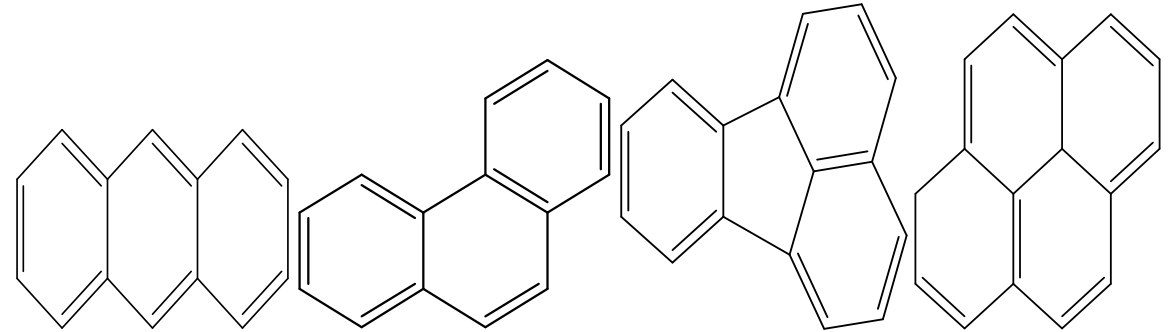

Anthracene $\left(\mathrm{M}_{\mathrm{w}}=178\right)$ phenanthrene $\left(\mathrm{M}_{\mathrm{w}}=178\right)$ Floranthene $\left(\mathrm{M}_{\mathrm{w}}=202\right)$ pyrene $\left(\mathrm{M}_{\mathrm{w}}=202\right)$

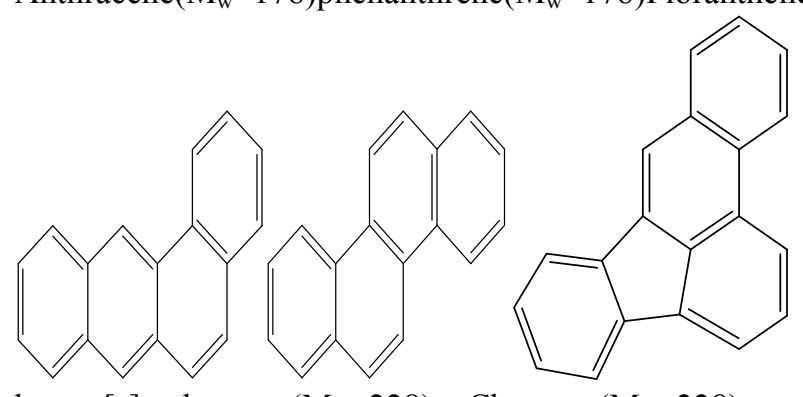

benzo $[a]$ anthracene $\left(\mathrm{M}_{\mathrm{w}}=228\right) \quad$ Chrysene $\left(\mathrm{M}_{\mathrm{w}}=228\right)$
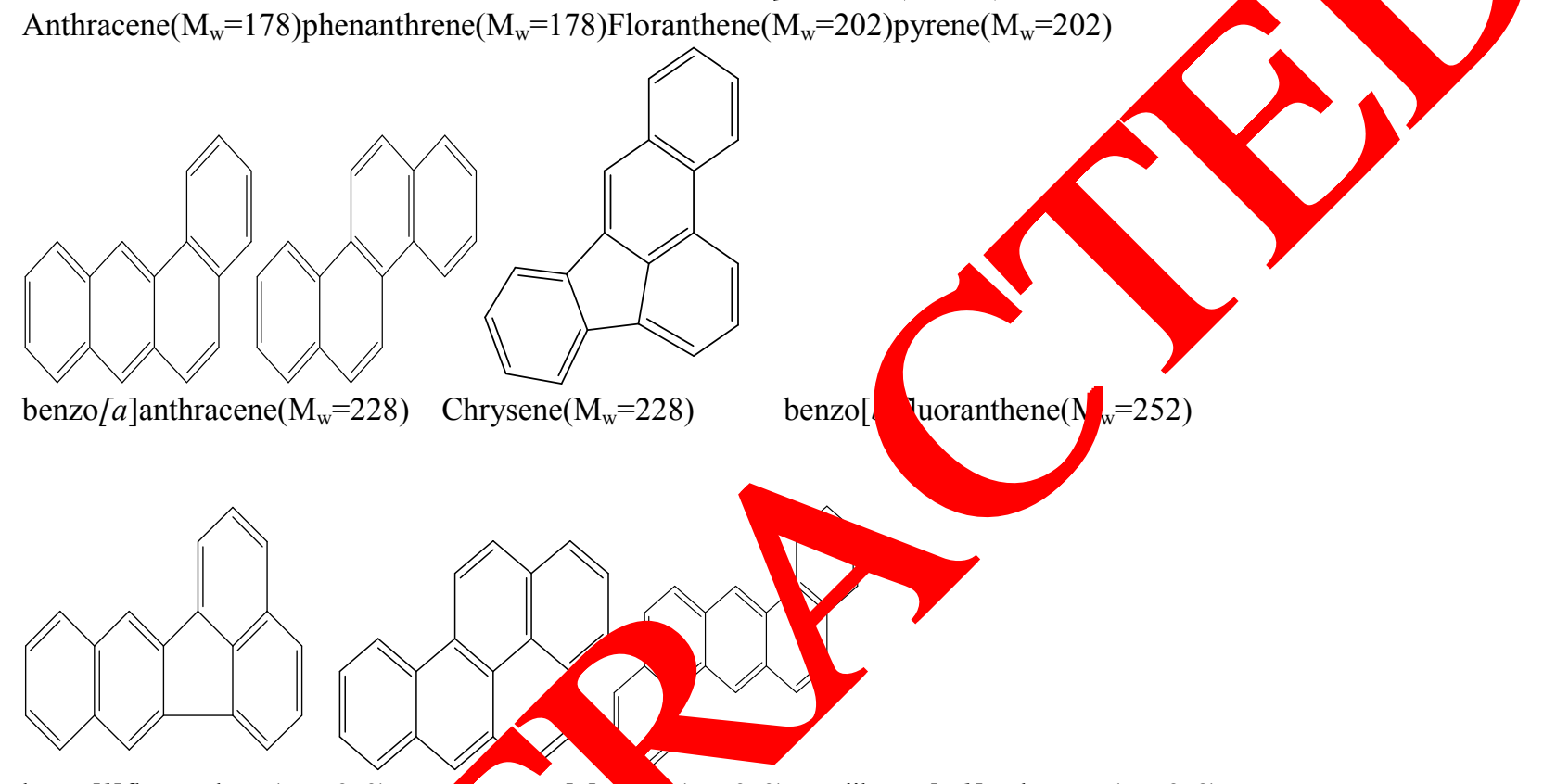

benzo $[k]$ fluoranthene $\left(\mathrm{M}_{\mathrm{w}}=252\right) \quad \operatorname{Benzo}[a]$ py $\left.\quad \mathrm{M}_{\mathrm{w}}, 252\right) \quad$ dibenzo $[a, h]$ anthracene $\left(\mathrm{M}_{\mathrm{w}} 278\right)$

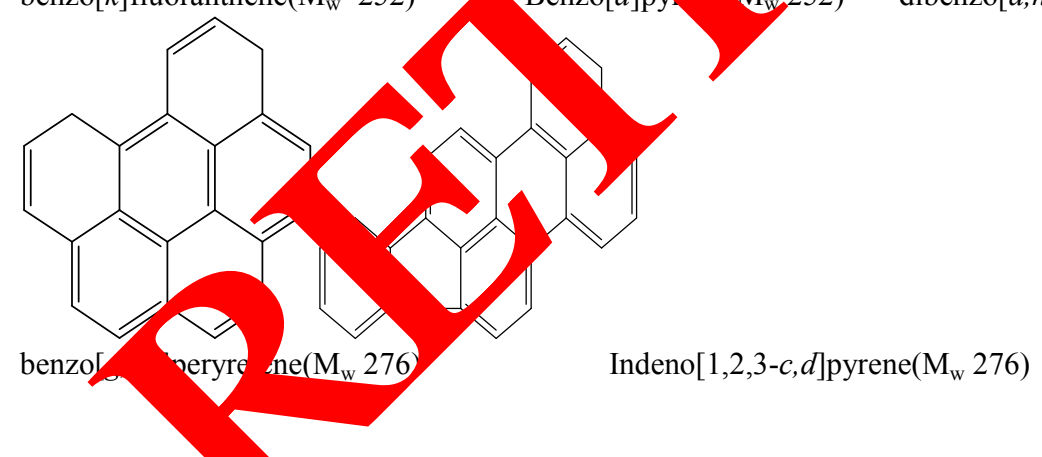

\subsubsection{Samplyalysis (GC-MS)}

The vials containing sample extractswere placedon GCMS auto-sampler tray for analysis. The instrument with instrumentation set-up described in section 2.3.1 above was set on to run the samples.

The GC-MS was calibrated using 0.5 - 10 ppm mixed PAH standards each containing 0.5 ppm of the PAH deuterated internal standard mix. Identification of the components of the standard and sample mixture was carried out by matching the specific mass to charge ion and retention time for each PAH component in the mixture with those of pure components analysed under the same experimental conditions. Also a calibration check was carried out to monitor the reliability of the calibration and confirm the retention time running any batch of samples. 


\subsection{Estimation of Freely Dissolved PAHs Concentrations}

Three methodologies were utilised in order to convert analytical data to comparable basis i.e. PAH $(\mathrm{ng} / \mathrm{L})$. Dissolved water concentrations $\left(\mathrm{C}_{\mathrm{w}}\right)$ were determined for sites using direct analysis of the water spot samples and Passive sampler derived $\mathrm{C}_{\mathrm{w}}$, using sampling rates $\left(\mathrm{R}_{\mathrm{S}}\right)$.

\subsubsection{Direct Analysis of the Water Spot Samples}

Direct analysis of the concentrations of freely dissolved contaminants was performed on unfiltered spot water samples obtained from Bridge of Buthlaw, Bridge at Mill of Gaval and Bridge of Inverugie. Monthly collection of samples from the site was carried out for six (6) months and quantified for PAHs.

\subsubsection{Analysis of Silicone Rubber sampler}

In order to ultimately yield an estimate of the freely dissolved aqueous-phase con trations $\mathrm{C}_{\mathrm{w}}$ ) from the passive sampling membranes, a number of data conversions and cocuration reg ared. This is achieved through the following stepwise process:-

- Assessment of appropriate PRCs.

- Calculation of the Passive Sampler Sampling Rate $\left(\mathrm{R}_{\mathrm{S}}\right)$.

- Conversion of PS membrane data into water concentrat ns.

\subsubsection{Assessment of appropriate PRCs}

The sampling rate $\left(\mathrm{R}_{\mathrm{S}}\right)$ can be simply described as the quivalent spot sample water volume that is sampled during a given time period. The sampling rat r each an lyte was determined using the dissipation rate of a performance reference compound sopiked onto the sampler prior to deployment. For the purpose of this work, the alimination constant $\left(\mathrm{K}_{\mathrm{e}}\right)$ was calculated using the dissipation rate of fluorene- $\mathrm{d}_{10}$ using equatio

$$
\mathrm{K}_{\mathrm{e}}\left(\text { day }^{-1}\right)=-\ln \left(\mathrm{C}_{\mathrm{t}} / \mathrm{C}\right.
$$

eqn. 1

Where $\mathrm{K}_{\mathrm{e}}$ is the elimination con $\mathrm{C}_{\mathrm{o}}$ are the concentrations of PRC at the time of retrieval and prior to deplo ent respe ely and $t$ is the deployment period (days).

On the basis of examina on the site sp ific datasets from James Huttons Institute and literature comparison, a number o.PRC, are found to be suitable internal standard for PAHs use (Yates et al 2007 and Smedes et al 2007). Aer to complete the process of the estimation of the sampling rate for this str $\mathrm{v}$, fluc ne- $\mathrm{d}_{10}$ was chosen as it is depleted to a measurable extent during the exposure period.

In ora to freely dissolved concentrations of contaminants, the calculated PRC eliminatio, instant $\left(\mathrm{K}_{\mathrm{e}}\right)$ was used to estimate sampling rate for the specific compound. Estimation of the samph Yate is effectively a measure of the degree of similarity between the PRCs in the original memoranes $(100 \%)$ and the remaining in the membranes after the exposure study. The sampling rate for the PRC in the sampler was calculated using the equation 2 below

$$
\mathrm{R}_{\mathrm{s}(\mathrm{PRC})}=\mathrm{K}_{\mathrm{e}} * \mathrm{M}_{\mathrm{s}} * \mathrm{~K}_{\mathrm{sw}}(\mathrm{L} / \text { day })
$$

eqn. 2

Where $K_{\mathrm{sw}}$ is the sampler-water partition coefficient $(\mathrm{L} / \mathrm{kg})$ and $\mathrm{M}_{\mathrm{s}}(\mathrm{kg})$ is the mass of the sampler used. 


\subsubsection{Conversion of Passive Sampling Membrane Data into Water Concentration}

For estimation of the freely dissolved concentration $\left(C_{w}\right)$ in the water phase the full uptake model valid for equilibrium and non-equilibrium situations is applied. The uptake is described by the equation 3 obtained from Smedes et al (2009):

Where:

$$
\mathrm{N}^{\mathrm{t}}=\mathrm{N}^{\infty}\left(1-\exp \left(\mathrm{R}_{\mathrm{s}} * \mathrm{t} / \mathrm{M}_{\mathrm{s}} * \mathrm{~K}_{\mathrm{sw}}\right)\right)
$$

eqn. 3

$N^{t}$ is the amount of compound (ng) in the sampler after deployment for time (in days), $N^{\infty}$ is the final amount taken up in the equilibrium situation,

$R_{\mathrm{S}}$ the sampling rate $(\mathrm{L} / \mathrm{d})$, the exposure time $(\mathrm{d}), M_{s}$ the mass of the sampler $(\mathrm{kg})$, and $K_{s w}$ is the silicone rubber-water partition co-efficient.

The final amount taken up in the equilibrium situation $\left(N^{\infty}\right)$ equals the equilibr concent ion $\left(\mathrm{Cs}^{\infty}\right)$ times the mass of the sampler $\left(\mathrm{M}_{\mathrm{s}}\right)$ in $\mathrm{kg} . \mathrm{C}_{\mathrm{s}}{ }^{\infty}$ is related to $C_{\mathrm{w}}$ by the $\mathrm{p}$ ation fficien $\mathrm{K}_{\mathrm{sw}}$ $(\mathrm{L} / \mathrm{kg})$ and consequently:

$$
\mathrm{N}^{\infty}=\mathrm{M}_{\mathrm{s}} * \mathrm{C}_{\mathrm{s}}^{\infty}=\mathrm{M}_{\mathrm{s}} * \mathrm{C}_{\mathrm{w}} * \mathrm{~K}_{\mathrm{sw}}
$$

And therefore,

$$
\mathrm{C}_{\mathrm{w}}=\mathrm{N}^{\infty} /\left(\mathrm{M}_{\mathrm{s}} * \mathrm{~K}_{\mathrm{sw}}\right)
$$

By combining eqn.4and eqn.5, the freely dissolved water concentrations $\left(C_{w}\right)$ in $n g / L$ were determined by means of the following equation:

$$
\mathrm{C}_{\mathrm{w}}=\left(\mathrm{N} /\left(\mathrm{m}^{*} \mathrm{~K}_{\mathrm{sw}}\right)\right) *\left(1 /\left(1-\exp -\left(\mathrm{R}_{\mathrm{s}} * \mathrm{t}\right) /(\mathrm{m}\right.\right.
$$

eqn. 6 In order to calculate $C_{w}$, silicone membrane spe tim ition constants $\left(K_{s w}\right)$ for PRC are required. These $K_{\mathrm{sw}}$ co-efficient were obtained in either of two vays; that is by utilising the $\mathrm{K}_{\mathrm{sw}}$ values available in the literature or by using timated (modelled) available literature data. $\mathrm{K}_{\mathrm{sw}} \mathrm{value}$ for the PRC used (fluorine- $\mathrm{d}_{10}$ ) was of ained om Smy cos (2007).

\section{RESULTS AND DIFCOSSI}

\subsection{Sampling Rates,}

The sampling rate of 8.41(L/day) using Fluorene- $\mathrm{d}_{10} \mathcal{C}$ dissipation (table 1 ). The data obtained from the PRC dissipation (a lo $\quad \mathrm{k}_{\mathrm{sw}} \mathrm{co}$ pound; fhuorene- $\mathrm{d}_{10}$ ) indicate that there is relatively slow kinetics transfer of the analytes a the ex sure time. A minimum concentration of $32 \%$ was recovered when compared n-dep sped silicone rubber sheets.

\begin{tabular}{|l|c|c|c|}
\hline Shole & Showin, the sampler weight, concentration and sampling rate of the site. \\
\hline Bridg of Inverugie & $\begin{array}{c}\text { Sampler weight } \\
(\mathrm{g})\end{array}$ & $\begin{array}{c}\text { Concentration of } \\
\text { fluorene- } \mathrm{d}_{10}(\mu \mathrm{g} / \mathrm{g})\end{array}$ & $\mathrm{R}_{\mathrm{s}}(\mathrm{L} / \mathrm{day})$ \\
\hline
\end{tabular}

\subsection{Freely dissolved PAHs concentrations}

\subsubsection{Spot water concentrations}

The mean concentrations of PAHs analytes obtained from the analysis of spot water samples collected from the sites every 4 weeks covering the period from 03/12/2013 to 28/04/2014 was presented in table 2 below. The concentrations were found to be below the limit of detection and limit of quantification (see appendix for LODs and LOQs values). This shows that all the PAHs were below the limit of detection. Thus, the analysis of PAHs using spot sampling methodologies is not reliable. 
Table 2: Mean water concentrations of PAHs (pg/L) of six different spot water sampling of the sites.

\begin{tabular}{|c|c|c|c|}
\hline \multirow[b]{2}{*}{ PAHs } & \multicolumn{3}{|c|}{ Concentration $(\mathrm{pg} / \mathrm{L})$} \\
\hline & Bridge of Buthlaw & $\begin{array}{c}\text { Bridge at Mill of } \\
\text { Gaval }\end{array}$ & Bridge of Inverugie \\
\hline Naphthalene & 38.1 & 1.8 & 27.4 \\
\hline 1-Methyl Naphthalene & 6.0 & 2.1 & 3.6 \\
\hline 2-Methyl Naphthalene & 6.1 & ND & 5.1 \\
\hline Acenaphthylene & 0.9 & 0.7 & 5.9 \\
\hline Acenaphthene & 11.4 & 10.6 & 12.1 \\
\hline Fluorene & 8.4 & 4.9 & \\
\hline Phenanthrene & 5.6 & 3.7 & \\
\hline Anthracene & 8.1 & 5.6 & \\
\hline Fluoranthene & 5.4 & 4.4 & \\
\hline Pyrene & 3.0 & 2.8 & \\
\hline Benz $[a]$ anthracene & 6.0 & 5.9 & \\
\hline Chrysene & ND & $\mathrm{N}$ & \\
\hline Benzo[b]fluoranthene & 7.5 & & 7.9 \\
\hline Benzo[k]fluoranthene & ND & & ND \\
\hline Benzo[a]pyrene & 6.0 & 6.0 & 6.2 \\
\hline Benzoperylene & ND & ND & ND \\
\hline
\end{tabular}

The freely dissolved concentration of PAHs o to ned om the sampler deployed at Bridge of Inverugie for period of 63 days is $n$ in ta e 3 below. Due to the analytes lost that was encountered during evaporation s $\mathrm{p}$ in le prepa Mon stage, freely dissolved concentrations of PAHs analytes of site 1 (Bridg 0 , th 8 (Bridge at Mill of Gaval) was not reported. Therefore, no comparison ca bermad the spot sampling data of those sites.

Table3.5: Showing the re dissolvea oncentration of PAHs obtained from silicone rubber

\begin{tabular}{|c|c|c|}
\hline & $\mathrm{Cw}$ (ng/L) & \\
\hline & 0.76 & BDL \\
\hline lethyl I shthalene & 0.21 & BDL \\
\hline thy Naphthalene & 0.17 & BDL \\
\hline Ace phthylene & 0.11 & BDL \\
\hline Achaphthene & 0.26 & BDL \\
\hline rluorene & 0.33 & $\mathrm{BDL}$ \\
\hline Phenanthrene & 0.61 & BDL \\
\hline Anthracene & 0.08 & $\mathrm{BDL}$ \\
\hline Fluoranthene & 0.49 & BDL \\
\hline Pyrene & 0.40 & BDL \\
\hline Benz[a]anthracene & 0.04 & BDL \\
\hline Chrysene & 0.07 & $\mathrm{BDL}$ \\
\hline Benzo $[b]$ fluoranthene & 0.05 & BDL \\
\hline Benzo[k]fluoranthene & 0.01 & BDL \\
\hline Benzo $[a]$ pyrene & 0.05 & BDL \\
\hline Benzoperylene & ND & ND \\
\hline
\end{tabular}

$\mathrm{ND}=$ not detected,

$\mathrm{BDL}=$ below detection limit 
Table 3.5 shows that using silicone rubber passive sampling method, 15 of 16 US-EPA PAHs compounds were detected with concentration ranging from 0.01 to $0.76 \mathrm{ng} / \mathrm{L}$ with naphthalene having the highest concentration. Although the silicone rubber sampler gives concentrations of PAHs analytes higher than that obtained from spot water sampling method, the concentration of the analytes were below the detection limit both in water and silicone rubber sampler see appendix.

Generally, the dissolved concentration of PAHs found in Ugie catchment was very low. From the result obtained, it is evident that low molecular weight PAHs (2- and 3-rings) were the most abundant while the high molecular weight (4-6-ring) was very little or not present. Also, the results indicate that PAHs in Ugie water were within the allowableconcentration.

The likely source of these PAHs can be identified by plotting the concentrations of the PAH ratios (Webster et al 2004). When ratio of fluoranthene and pyrene was calculated; greater thom $1(>1)$ is an indicative of pyrolytic source of PAHs while less than $1(<1)$ indicates the petrogenic ces. From the silicone rubber passive sampler result, the fluoranthene/pyrene ratio $\mathrm{W}, 1$ and thi ive an insight that the source of PAHs found in Ugie catchment was most likely pyolyt hich m be from incomplete combustion of organic materials, combustion of fossil fy cls, coal an from incineration of agricultural, industrial or municipal waste.

\section{CONCLUSION}

Freely dissolved concentrations of PAHs in Ugie water cet uccessful cermined using SR-PS devices. The study shows the sensitivity of silic ge ru passive sampling over conventional spot water sampling for identification of po sy ic aroma ydrocarbons in surface water systems. The freely dissolved PAH concentration of SR-PS were found to be higher than that found in spot samples.

The PRC derived in situ sampling rates of 8.14 ay) for s licone rubber passive samplers were observed. Analysis of PRC compound (f furene- $\mathrm{d}_{10}$, nat there is slow kinetic exchange between the sampled analyte and PRC compo kinetic exchange can be influenced by a number of variables including hydrodynamic, fo linc, an dinity which suggest the sampling rates
of the exposure site.

The result presented shows th at th n-quan fied PAHs entering the river of Ugie catchment may be as results of agriculty and elated 1, nd use practices or atmospheric depletion of

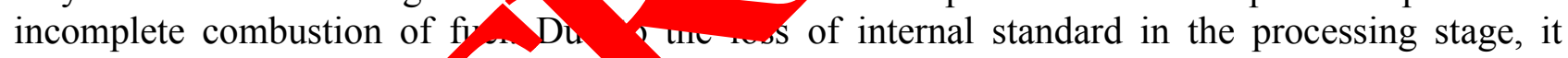
becomes difficult to comp? south and Ugie water so as to identify the source of these PAHs compound detected.

Going by the wate ramework Directive (2000/60/EC) on priority and hazardous substances the corcentration of $\mathrm{P}_{2}$ s compound found by SR-PS device in this study was within the tolerable liv for s and long term exposure. Thus, it can be concluded that use of SR-PS devices in monito organic contaminant like PAHs was a viable alternative to conventional spot water sam meth

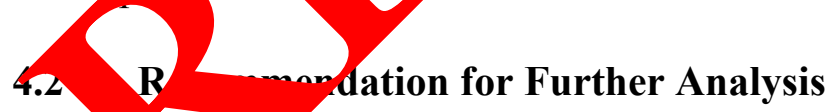

During th tudy it has become evident that there are a number of areas in which it could proceed. Future studio hould focus on:

- Performing a larger study combining passive samplers (in appropriate areas) to further illustrate the effectiveness of the samplers as environmental monitors and begin a database for freely dissolved concentrations of contaminants of interest.

- Investigating which other contaminants may be taken up by the silicone rubber passive samplers; these might include other hydrophobic contaminants which have $\log \mathrm{K}_{\mathrm{ow}}$ ranges between 3 and 8 , such as pesticides and herbicides.

- Look at seasonal changes and how they affect freely dissolved contaminant concentrations.

- Investigate the effect of variables such as hydrodynamics and salinity on sampling rates. 


\section{Appendix 1}

Table 3.2: Showing the equation of the line, $r^{2}$ value, and LOD \& LOQ (ng/L) of 16 PAHs compounds.

\begin{tabular}{|c|c|c|c|c|c|c|c|}
\hline PAHs & $\begin{array}{c}\text { EQUATION OF } \\
\text { LINE }\end{array}$ & $\begin{array}{c}\mathbf{R} \\
\text { Square }\end{array}$ & LOD & LOQ & $\begin{array}{c}\text { LOD } \\
\text { SR } \\
\text { sampler }\end{array}$ & $\begin{array}{l}\text { No of } \\
\text { point } \\
\text { used }\end{array}$ & Int. std used \\
\hline Naphthalene & $\begin{array}{c}\mathrm{Y}=0.1348 \mathrm{X}+ \\
0.0601\end{array}$ & 0.9991 & 310 & 1040 & 3.29 & 5 & Naphthalene- $\mathrm{D}_{10}$ \\
\hline 2-Methylnaphthalene & $\begin{array}{c}\mathrm{Y}=0.0713 \mathrm{X}- \\
0.0031\end{array}$ & 0.9999 & 120 & 410 & 0.51 & 5 & Naphthaler \\
\hline 1-Methylnaphthalene & $\begin{aligned} \mathrm{Y}= & 0.0731 \mathrm{X}+ \\
& 0.0104\end{aligned}$ & 0.9999 & 120 & 410 & 0.46 & 5 & \\
\hline Acenaphthylene & $\begin{array}{c}\mathrm{Y}=0.2169 \mathrm{X}- \\
0.0185\end{array}$ & 0.9999 & 140 & 470 & 2.03 & & \\
\hline Acenaphthene & $\begin{array}{c}\mathrm{Y}=0.1482 \mathrm{X}- \\
0.1539\end{array}$ & 0.9935 & 1030 & 3420 & & & \\
\hline Fluorene & $\begin{array}{c}\mathrm{Y}=0.1244 \mathrm{X}- \\
0.0511\end{array}$ & 0.9982 & 450 & & & 5 & $\begin{array}{c}\text { Acenaphthene- } \\
D_{10}\end{array}$ \\
\hline Phenanthrene & $\begin{array}{c}\mathrm{Y}=0.1505 \mathrm{X}- \\
0.0280\end{array}$ & 0.9917 & 1200 & 4010 & 3.99 & 6 & Phenanthrene- $\mathrm{D}_{10}$ \\
\hline Anthracene & $\begin{array}{c}\mathrm{Y}=0.1098 \mathrm{X}- \\
0.0328\end{array}$ & 0.998 & & & & 5 & Phenanthrene- $\mathrm{D}_{10}$ \\
\hline Fluoranthene & $\begin{array}{c}\mathrm{Y}=0.0744 \mathrm{X}- \\
0.0259\end{array}$ & 0.9968 & & 1980 & 1.55 & 5 & Phenanthrene- $\mathrm{D}_{10}$ \\
\hline Pyrene & & .9949 & 710 & 2380 & 1.79 & 6 & Phenanthrene- $\mathrm{D}_{10}$ \\
\hline Benz $[a]$ anthracene & & & 440 & 1450 & 0.86 & 5 & Chrysene- $\mathrm{D}_{12}$ \\
\hline Chrysene & & 0.9992 & 370 & 1220 & 0.74 & 4 & Chrysene- $\mathrm{D}_{12}$ \\
\hline & & 0.9937 & 1160 & 3110 & 2.20 & 5 & perylene- $\mathrm{D}_{12}$ \\
\hline & & 0.9969 & 590 & 1960 & 1.12 & 5 & perylene- $\mathrm{D}_{12}$ \\
\hline Ben & $\begin{array}{c}\mathrm{Y}=0.1279 \mathrm{X}- \\
0.0731\end{array}$ & 0.9942 & 810 & 2690 & 1.54 & 5 & perylene- $\mathrm{D}_{12}$ \\
\hline Benzo $[g h i] p_{4}$ & $\begin{array}{c}\mathrm{Y}=0.1153 \mathrm{X}+ \\
0.0158\end{array}$ & 0.9982 & 530 & 1800 & 1.00 & 4 & perylene- $\mathrm{D}_{12}$ \\
\hline
\end{tabular}

indeno[1,2,3-cd]pyrene and dibenzo $[a, h]$ anthracene were not reported because of their poor calibration observed during the analyses $\left(\mathrm{r}^{2}<0.99\right)$. 
Appendix 2

Typical Chromatograms

Calcheck Chromatogram (5ppm)

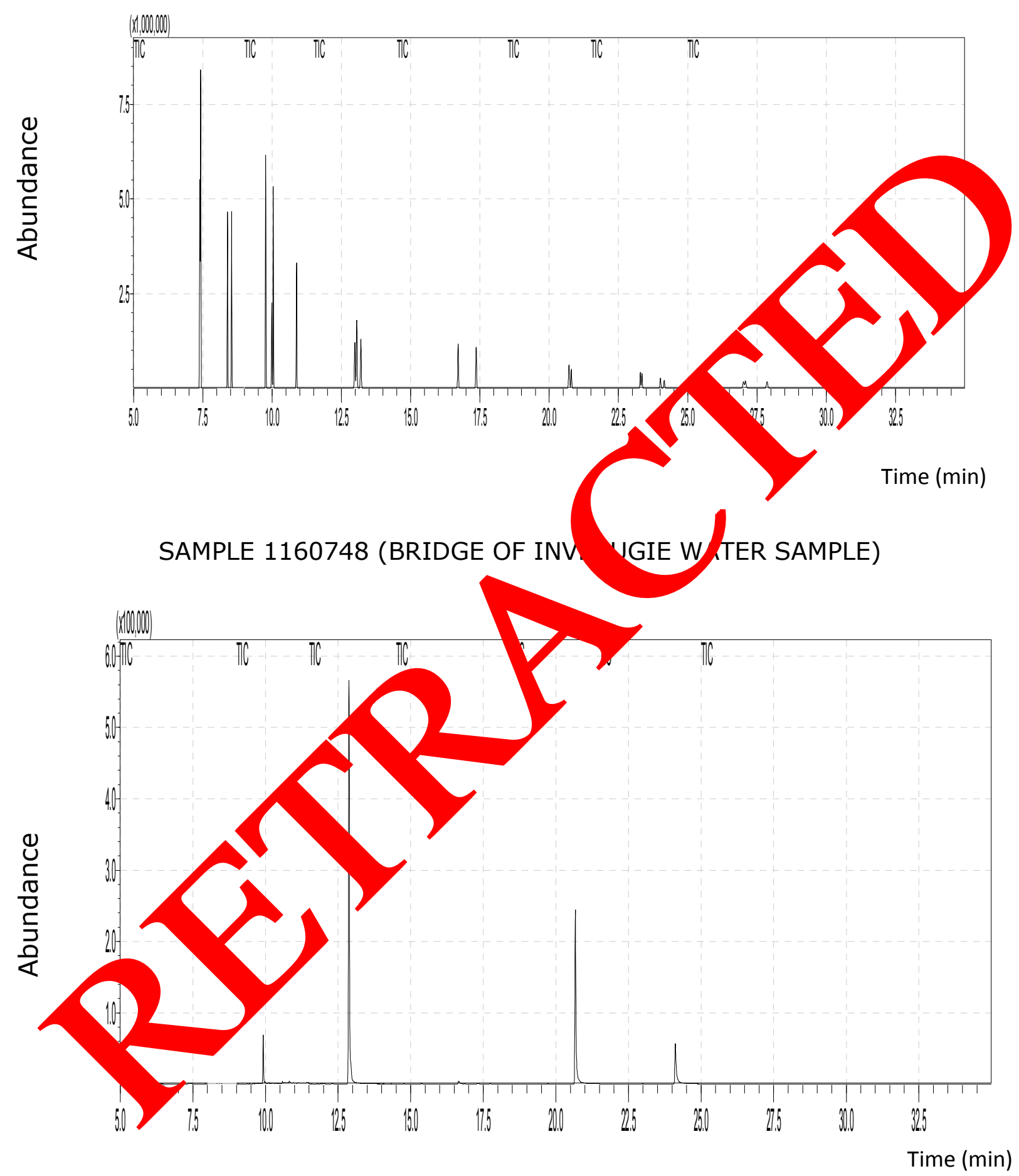

SR 1160748(BRIDGE OF INVERUGIE SILICONE RUBBER) 


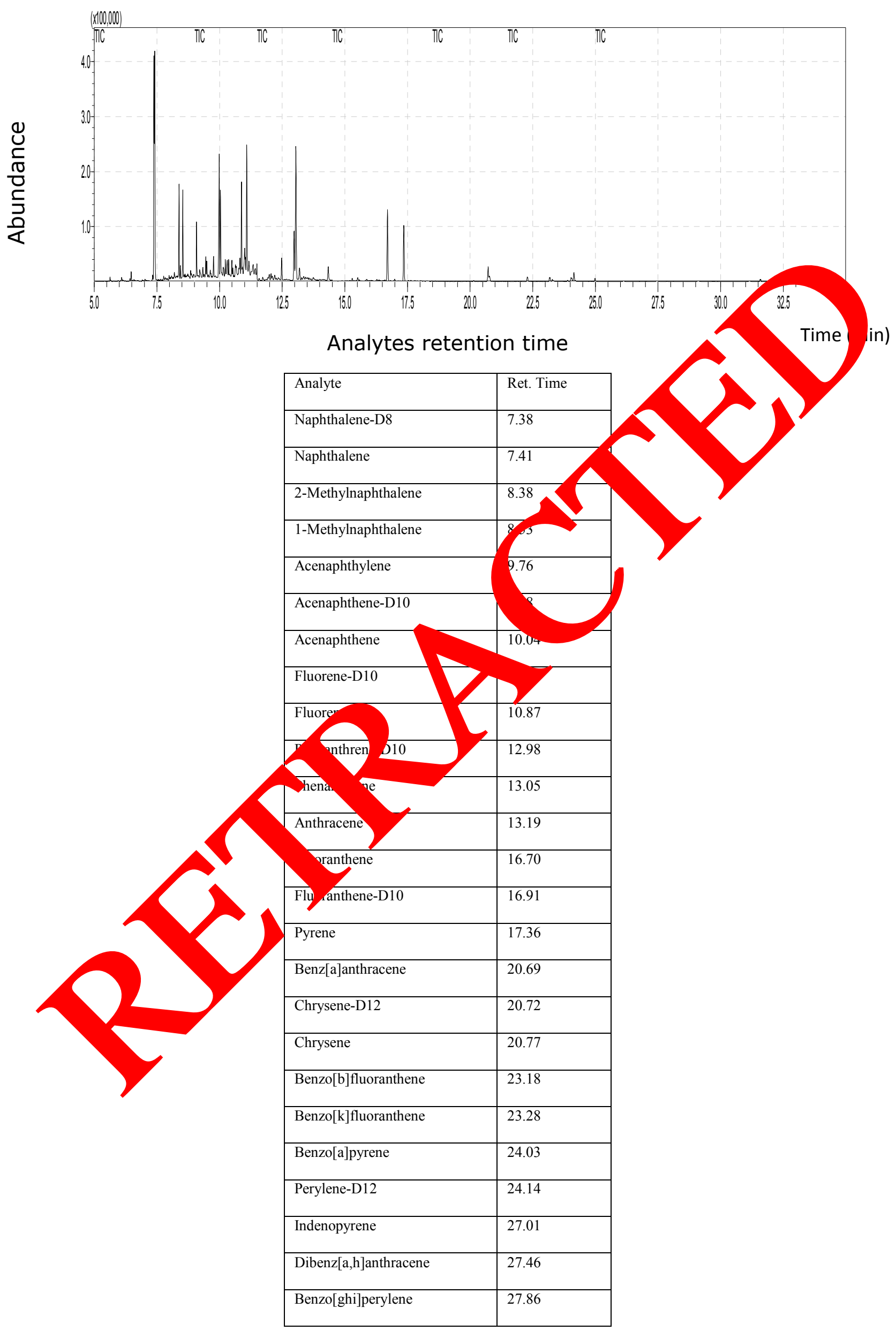




\section{References}

[1] BOOIJ, K., et al., 2000. Passive Sampling of Organic Contaminants in the Water Phase.Final Report.The Netherlands Institure for Sea Research.NIOZ report 2000-5. [Online] Available from www.nioz.nl/public/nioz_reports/nioz-report_2000-5.pdf (accessed on 20/04/14)

[2] BOOIJ, K., et al., 2002. Spiking of performance reference compounds in low density polyethylene and silicone passive water samplers. Chemosphere, 46, pp. 1157-1161

[3] EMELOGU, E.S., et al., 2012. Investigating the significance of dissolved organic contaminants in aquatic environments: Coupling passive sampling with in vitro bioassays. Chemosphere, 90, pp. 210-219.

[4] EMELOGU, E.S., et al., 2013a. Occurrence and potential combined toxicit or lved organic contaminants in the Forth estuary and Firth of Forth, Scotland asse d using p ive samplers and an algal toxicity test. Science of the Total Environment, 461-46, 230-2.

[5] EMELOGU, E.S. et al., 2013b. Identification of selected organic ontaminan. reams associated with agricultural activities and comparison between tosam ing an silicone rubber passive sampling. Science of the Total Environment, $445, \mathbf{4 6}, 261-27$ [6] GORECKI, T. and NAMIENIK. J., 2002.Passive samplin rends in A racal Chemistry.
21(4)pp. 276-291.

[7] HUCKINS, J.N. et al., 1993. Lipid-containing sempermeab Membrane devices for monitoring organic contaminants in water.Envi onmental Scienc and Technology.27(12) pp.2489-2496.

[8] HUCKINS, J.N. PETTY and BOOIJ, K., 200 Monito of organic chemicals in the environment: Semipermeable Membrane ices. Sprriger, New York.

[9] KOT-WASIK, A. et al., 2007. Ad nce passive sampling in environmental studies.AnalyticaChimicaActa.602(2) pp. 14, 163.

[10] KOT, A. ZABIEGADLA, $P$ and AMIES YK, J., 2000. Passive sampling for long-term monitoring of organic polata in

[11] MADRID, Y. and ZA AS, Z.P., 07. Water sampling: Traditional methods and

[12] new approaches i wato mpling srategy. Trends in Analytical Chemistry.

[13] 26(4)pp. 293 -299.

[14] MAYER et a1 90 A.Sensing Dissolved Sediment Porewater Concentrations of Persistent and Bioaco Alative ollutants Using Disposable Solid-Phase MicroextractionFibers. Eny entat inc and Technology. 34(24)pp. 5177-5183.

[15] TSIN . T.P., etal., 2007. Polymer selection for passive sampling: A comparison of critical pro nosphere, 68, pp. 1344-1351.

[16] SMED ., 2007. Chapter 19: Monitoring of chlorinated biphenyls and polycyclic aromatic hydroca ons by passive sampling in concert with deployed mussels. In R. Greenwood, G. Mills and B. Vrana (editors).(2007). "Passive Sampling Techniques in Environmental Monitoring." Elsevier

[17] SMEDES, F., and BOOIJ, K. 2012.Guidelines for passive sampling of hydrophobic contaminants in water using silicone rubber samplers.ICES Techniques in Marine Environmental Sciences, No. 52, PP. 1-20.

[18] VRANA, B. et al., 2005. Passive sampling techniques for monitoring pollutants in water.Trends in Analytical Chemistry, 24(10), pp. 845-868. 
[19] VRANA, B. et al., 2006. Calibration of the Chemcatcher passive sampler for the monitoring of priority organic pollutants in water.Environmental Pollution. 142(2), pp. 333-343.

[20] VRANA, B., PASCHKE, A. and POPP, P. 2006. Calibration and field performance of membrane-enclosed sorptive coating for integrative passive sampling of persistent organic pollutants in water.Environmental Pollution.144(1), pp. 296-307.

[21] YATES, K., et al., 2007.Passive sampling: Partition coefficients for a silicone rubber reference phase. Journal of Environmental Monitoring, 9(10), pp. 1116-1121

[22] YATES, K., et al., 2011. Application of silicone rubber passive samplers to investigate the bioaccumulation of PAHs by Nereisvirensfrom marine sediments. Environmental Pollution, 159, pp. 3351-3356

[23] YATES, K., et al., 2013. Silicone rubber passive samplers for measurin pore wato and exchangeable concentrations of polycyclic aromatic hydrocarbons co antration in sediments. Science of the Total Environment, 463-464, pp. 988-996

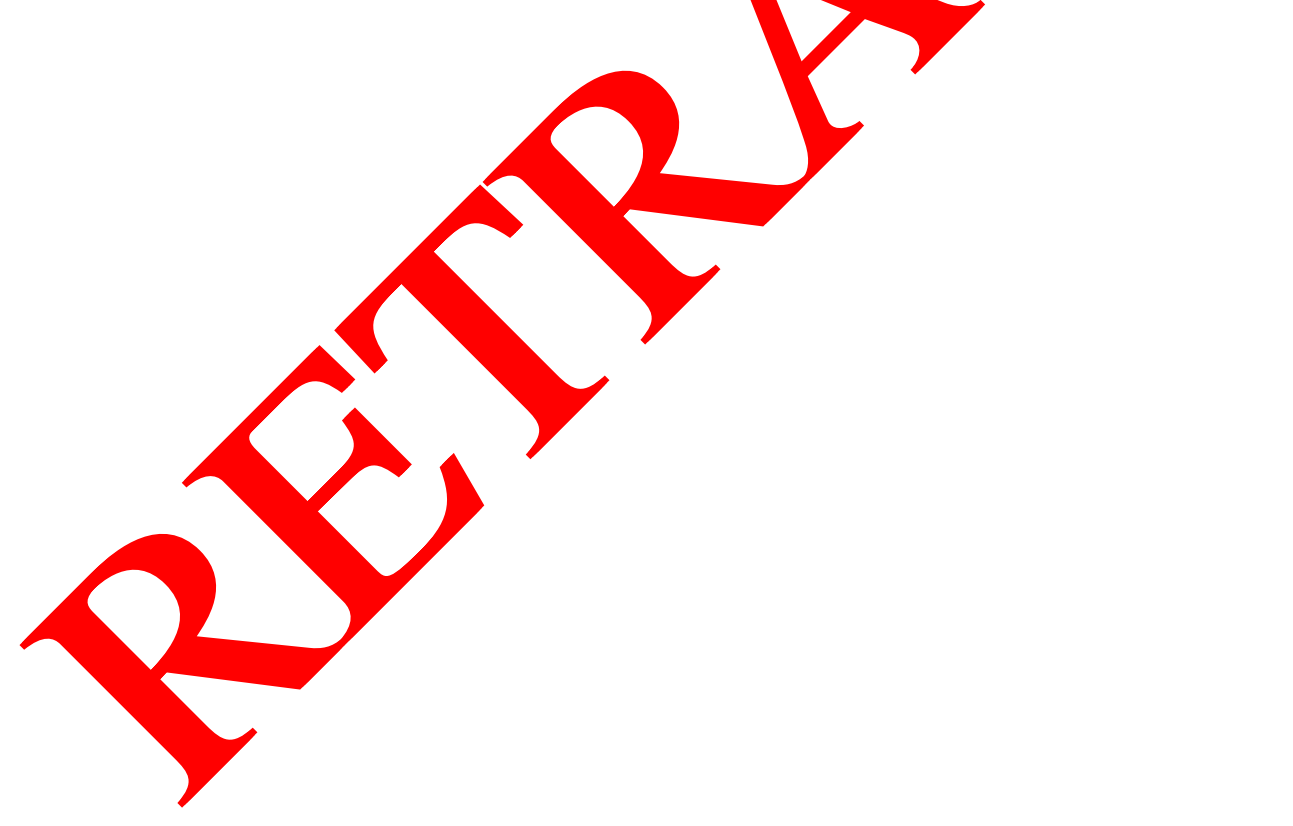

